\title{
Chapter 22 \\ Life Cycle Management Applied to Urban Fabric Planning
}

\author{
Xavier Gabarrell, Joan Rieradevall, Alejandro Josa, Jordi Oliver-Solà, \\ Joan Manuel F. Mendoza, David Sanjuan-Delmás, Anna Petit-Boix, \\ and Esther Sanyé-Mengual
}

\begin{abstract}
Due to the rapid urbanization and the large contribution of cities to the global environmental impact, urban policies integrate sustainability in the public space design. Current literature has accounted for the environmental impact of the main elements of the urban fabric, although studies have dealt with them individually. This chapter aims to optimize the environmental performance of the urban fabric for supporting planning processes, based on existing life cycle assessment (LCA) data of the main elements of urban fabric: sidewalks, pavements, and the gas, water and wastewater networks. Material selection and lifespan are key issues in the
\end{abstract}

X. Gabarrell $(\bowtie) \bullet J$. Rieradevall

Sostenipra (ICTA-IRTA-Inèdit; 2014 SGR 1412)-Institut de Ciència i Tecnologia Ambientals (ICTA), Universitat Autònoma de Barcelona (UAB), Bellaterra, Spain

Department of Chemical Engineering, Universitat Autònoma de Barcelona, Bellaterra, Spain e-mail: Xavier.Gabarrell@uab.cat
A. Josa
Department of Geotechnical Engineering and Geosciences, School of Civil Engineering, Universitat Politècnica de Catalunya-Barcelona Tech (UPC), Barcelona, Spain
Institute of Sustainability, UPC, Barcelona, Spain
J. Oliver-Solà
Sostenipra (ICTA-IRTA-Inèdit; 2014 SGR 1412)-Institut de Ciència i Tecnologia Ambientals (ICTA), Universitat Autònoma de Barcelona (UAB), Bellaterra, Spain
Inèdit. Inèdit Innovació, S.L. UAB Research Park, Cabrils, Spain
J.M.F. Mendoza
Sostenipra (ICTA-IRTA-Inèdit; 2014 SGR 1412)-Institut de Ciència i Tecnologia Ambientals (ICTA), Universitat Autònoma de Barcelona (UAB), Bellaterra, Spain

Sustainable Industrial Systems (SIS) Group, School of Chemical Engineering and Analytical Science, University of Manchester, Manchester, UK

D. Sanjuan-Delmás • A. Petit-Boix • E. Sanyé-Mengual

Sostenipra (ICTA-IRTA-Inèdit; 2014 SGR 1412)-Institut de Ciència i Tecnologia Ambientals (ICTA), Universitat Autònoma de Barcelona (UAB), Bellaterra, Spain

G. Sonnemann, M. Margni (eds.), Life Cycle Management,

LCA Compendium - The Complete World of Life Cycle Assessment,

DOI 10.1007/978-94-017-7221-1_22 
environmental profile of the paved skin, while the installation accounts for the greatest share of the burdens in subterranean networks. The best design consists of concrete sidewalks, asphalt pavements, HDPE (high density polyethylene) gas pipes, PVC (polyvinyl chloride) water pipes, and concrete sewer pipes. Pavements and sidewalks are the most contributing elements to the overall environmental burdens of streets.

Keywords City developments $\bullet$ Life cycle assessment $\bullet$ Life cycle management - Life cycle thinking $\bullet$ Pavements $\bullet$ Sidewalks $\bullet$ Sustainability

\section{Introduction}

More than $50 \%$ of world's population is concentrated in cities, although they occupy less than $2 \%$ of the Earth's surface. Because of the intense activity of cities, which play an essential role in the global socio-economic development, they consume over $75 \%$ of the world's resources, between $60 \%$ and $80 \%$ of total energy, and are responsible for approximately $75 \%$ of global greenhouse gas (GHG) emissions (Ash et al. 2008; Kamal-Chaoui and Robert 2009; Pacione 2009; UN Population Division 2010; European Union 2011; Lazaroiu and Roscia 2012). Environmental awareness of the urban metabolism has raised due to the rapid urbanization patterns. As a result, policy and planning highlight the importance of promoting environmental strategies that increase the sustainability of cities (UN 2013).

Within cities, public spaces play a key role in supporting daily urban life. According to UN-HABITAT (2013a, b, c, d), four main issues might be considered. First, streets may become a matrix which increases the urban connectivity between people and activities thereby making mobility more efficient. Second, the street pattern hosts urban basic services, such as water supply. Third, public space is a key element for the cultural and political dimensions of cities. Finally, street design might enable the pedestrian and road mobility in a safe manner. Thus, streets are composed of multiple elements from diverse natures that satisfy the different functionalities of the public space (UN-HABITAT 2014).

The urban fabric is in constant change because of new city developments, maintenance and partial renewals due to the intense urban activity. The World Wide Fund for Nature (WWF) accounted for $\$ 350$ trillion of expenditure on urban infrastructures in the coming decades. Assuming business-as-usual (BAU) conditions, these projects would contribute to around 465 Gt of GHG emissions (WWF 2008). Then, if no environmental criteria are applied in the urban planning design (i.e., aesthetic or economic criteria are prioritized), the global environmental burdens of cities can dramatically increase. Furthermore, the consideration of all the life cycle stages to account for the environmental burdens of urban elements is basic for understanding their environmental performance, as demonstrated by Oliver-Solà et al. (2009a, b, c), Mendoza et al. (2012a, b), Petit-Boix et al. (2014), Sanjuan-Delmás et al. (2014). 
The general aim of this chapter is to incorporate the life cycle thinking approach into the design of the urban fabric for supporting planning processes, thereby optimizing the environmental performance of cities. The objective is to identify the best environmental practices by comparing existing LCA data of the main elements of the urban fabric (sidewalks, pavements, and the gas, water and wastewater networks) and to integrate these practices into the environmental impact accounting of the entire street profile.

\section{Methods}

\subsection{Environmental Benchmarking}

Life cycle assessment (LCA) (ISO 2006) is a tool for the systematic compilation and evaluation of the environmental aspects and the potential environmental impacts of products systems throughout their life cycle, from raw material acquisition through use until final disposal (UNEP/SETAC 2012). In this sense, the environmental benchmarking of multiple alternatives for urban fabric planning was conducted by reviewing LCA studies on their environmental impacts. To do so, different constructive solutions for sidewalks, pavements, and gas, water and wastewater networks were compared in terms of global warming potential (GWP; $\mathrm{kg}$ of $\mathrm{CO}_{2}$ eq.) (IPCC 2007).

\subsection{The Urban Fabric}

Multiple elements compose the urban fabric where daily urban life is supported. In this study, the authors considered the paved skin (sidewalks, road pavement) and the subterranean pipelines that supply basic services (gas, water, wastewater). Figure 22.1 displays a scheme of the urban fabric system. The functional unit of the assessment is a $1 \times 8 \mathrm{~m}$ street section in a time frame of 50 years, representative of a European medium-sized city. In particular, the scenario considers a street profile located at the city centre where light-weight traffic and pedestrian areas are preferential. Superficial structures such as benches or streetlights were excluded.

\section{Environmental Profile of Urban Fabric Elements}

The following section describes the environmental profile of multiple design options for the urban fabric. Once compared, the best practices are assembled to show an optimized design of the paved skin (sidewalks, road pavement) and the subterranean pipelines that supply basic services (gas, water, wastewater) from an environmental point of view. 


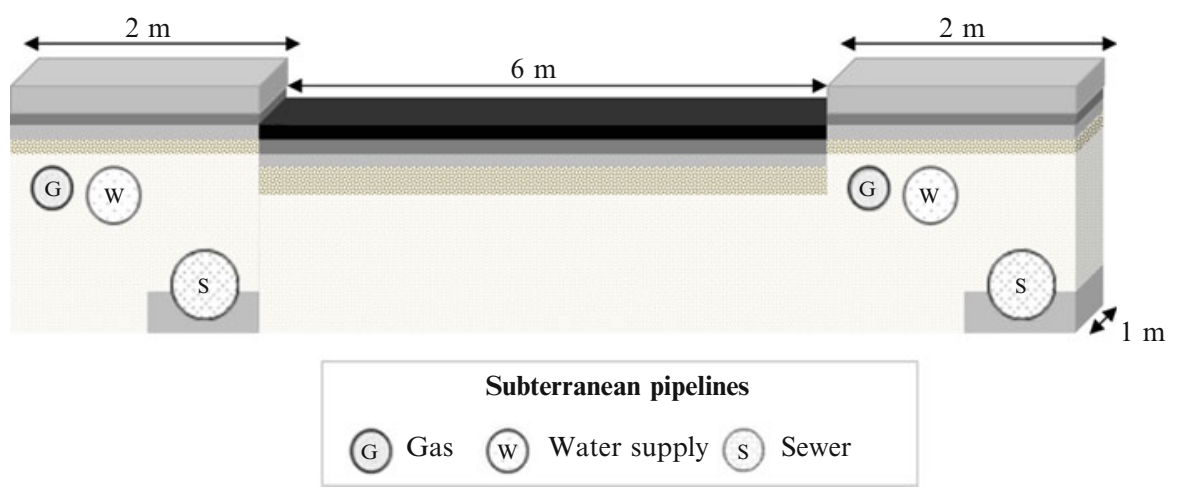

Fig. 22.1 The urban fabric: profile of the paved skin and subterranean pipelines under assessment

Table 22.1 Global warming potential (GWP) ( $\mathrm{kg}$ of $\mathrm{CO}_{2}$ eq.) of different pavement solutions for a functional unit of $1 \mathrm{~m}^{2}$ in a time frame of 50 years and renovation scenarios

\begin{tabular}{l|l|l|l}
\hline Pavement designs & $\begin{array}{l}\text { Reference } \\
\text { service life }\end{array}$ & $\begin{array}{l}\text { High renovation rate } \\
\text { (lifespan: 15 years) }\end{array}$ & $\begin{array}{l}\text { Low renovation rate } \\
\text { (lifespan: 40 years) }\end{array}$ \\
\hline Concrete top-layer & 79 & 129 & 82 \\
\hline Granite top-layer & 109 & 221 & 117 \\
\hline Asphalt top-layer & 84 & 84 & - \\
\hline
\end{tabular}

Note: The reference service life of sidewalks designs are 15 years for asphalt and 45 years for concrete and granite

\subsection{Paved Skin: Sidewalks and Light-Weight Traffic Road Pavement}

Table 22.1 shows the environmental impact of conventional designs of concrete, asphalt and granite sidewalks to support pedestrian and light-weight traffic in cities. The design solutions have different service lives: 15 years for asphalt and 45 years for concrete and granite. However, the GWP of each sidewalk changes according to the variability of the service life of the constructive solutions. The shorter the service life, the higher the number of maintenance and removal operations (top-layer replacement) to restore the serviceability of the sidewalks during the period of analysis (50 years). Thus, two maintenance scenarios were considered, e.g., high and low maintenance rates. During this time frame, the most environmentally friendly pavement design is the concrete top-layer, which had a GWP $6 \%$ and $28 \%$ lower than asphalt and granite, respectively.

However, the environmental performance of pavements strongly depends on their service life and a sensitivity assessment was conducted for a range of lifespan from 5 to 45 years. When the same service life is considered for the three solutions (i.e., lifespan is equivalent under certain exposure conditions), asphalt becomes the 
Table 22.2 Global warming potential (GWP) ( $\mathrm{kg}$ of $\mathrm{CO}_{2}$ eq.) of a natural gas network design for a time frame of 50 years for low and high density scenarios

\begin{tabular}{l|l|l|l|l|r}
\hline Urban density & Neighborhood & Buildings & Dwellings & Waste treatment & Total \\
\hline Low & 6290 & 905 & 1160 & 866 & 9221 \\
\hline High & 6290 & 30,000 & 75,100 & 4030 & 115,420 \\
\hline
\end{tabular}

best practice: in urban areas with a high renovation rate of sidewalks and lightweight traffic pavements ( $\leq 15$ years), asphalt is recommended for both sidewalks and light-weight traffic pavements: in contrast, concrete is the most suitable option in urban areas with a low renovation rate of sidewalks ( $>40$ years), whereas asphalt has a maximum lifespan of 15 years and a high renovation rate is unfeasible. In general, granite sidewalks are less environmentally due to the high resource intensive manufacture of granite tiles (Mendoza et al. 2012a, b, 2014a).

\subsection{Gas Network}

Table 22.2 shows the environmental impact of natural gas distribution networks for low and high density neighborhood scenarios. Contrary to other elements, the gas network only considers a standard constructive design - i.e., HDPE (high density polyethylene) pipes for medium-pressure gas distribution - and instead of multiple materials, scenarios compared urban densities. The studied system is a standard local neighborhood. The scenarios considered recreate one low density detached house neighborhood (4 dwellings) and a high density Mediterranean neighborhood (24 dwellings). The assessment includes the network in the neighborhood $(100 \mathrm{~m})$, the elements of the gas distribution in the buildings and the dwellings, and the waste treatment of the materials. The results show that the distribution of the environmental load between subsystems changes radically according to urban density. This means that in low-density areas the neighborhood network is the subsystem that gives raise to most impact (68\%), while in high-density neighborhoods the building and dwelling subsystems are those that are responsible for more than $95 \%$ of the GWP (Oliver-Solà et al. 2009a, b). For the purpose of our study, the impact of the neighborhood network was considered in the profile of the street (see Table 22.5).

\subsection{Water Supply Network}

Table 22.3 displays the environmental impacts of the drinking water network considering constructive solutions with different pipe materials and diameters. The environmental burdens were related to a functional unit of 1 linear meter of network. High and low density polyethylene (HDPE, LDPE) and polyvinyl chloride (PVC) were compared for a pipe with a diameter of $90 \mathrm{~mm}$, and HDPE, PVC, glass fiber 
Table 22.3 Global warming potential (GWP) ( $\mathrm{kg}$ of $\mathrm{CO}_{2}$ eq.) of different water supply constructive solutions for a functional unit of $1 \mathrm{~m}$ of pipe in a time frame of 50 years

\begin{tabular}{l|c|l|l|l|l|l|l}
\hline & \multicolumn{3}{|l}{ 90 mm-diameter pipes } & \multicolumn{3}{l}{ 200 mm-diameter pipes } \\
\cline { 2 - 8 } Stage & HDPE & LDPE & PVC & HDPE & PVC & GFRP & DI \\
\hline Production & 4.03 & 6.93 & 3.56 & 13.6 & 12.3 & 49.9 & 131 \\
\hline Transport & 8.73 & 8.94 & 8.70 & 9.83 & 9.71 & 9.73 & 16.2 \\
\hline Installation & 12.5 & 12.5 & 12.5 & 13.3 & 13.3 & 13.3 & 13.3 \\
\hline Total & 25.3 & 28.4 & 24.8 & 36.7 & 35.4 & 73.0 & 161 \\
\hline
\end{tabular}

Table 22.4 Global warming potential (GWP) ( $\mathrm{kg}$ of $\mathrm{CO}_{2}$ eq.) of different sewer constructive solutions with a diameter of $300 \mathrm{~mm}$ for a functional unit of $1 \mathrm{~m}$ of pipe in a time frame of 50 years

\begin{tabular}{l|l|l|l|l|l|c}
\hline & \multicolumn{3}{|l}{$\begin{array}{l}\text { HDPE (lifespan: } \\
\text { 50 years) }\end{array}$} & $\begin{array}{l}\text { PVC (lifespan: } \\
\text { 50 years) }\end{array}$ & \multicolumn{2}{l}{$\begin{array}{l}\text { Concrete (lifespan: } \\
\text { 100 years) }\end{array}$} \\
\cline { 2 - 8 } Life-cycle stage & PP1 & PP2 & PP1 & PP2 & CP1 & CP2 \\
\hline Pipe production & 23.7 & 23.7 & 7.2 & 7.2 & 4.8 & 4.8 \\
\hline Transport & 35.1 & 21.1 & 34.8 & 20.8 & 10.2 & 11.0 \\
\hline Installation & 33.2 & 125 & 33.2 & 125 & 42.3 & 65.0 \\
\hline Demolition & 0.95 & 1.20 & 0.95 & 1.20 & 0.60 & 0.60 \\
\hline Total impact & 93.0 & 171 & 76.2 & 154 & 57.9 & 81.4 \\
\hline
\end{tabular}

reinforced polyester (GFRP) and ductile iron (DI) for $200 \mathrm{~mm}$ (Sanjuan-Delmás et al. 2014). The life cycle stages included were the production, transport, and installation. The operation was excluded because it depends on the specific network. The end of use phase was also omitted since the supply network is left underground after its use.

In water supply network solutions, the installation stage contributed the most to the GWP (around $50 \%$ for $90 \mathrm{~mm} ; 10-40 \%$ for $200 \mathrm{~mm}$ ). Furthermore, the relevance of the installation phase was higher for smaller diameters, since the pipe required a lower amount of material and, thus, production is less impacting (15-25\% for $90 \mathrm{~mm}, 35-80 \%$ for $200 \mathrm{~mm}$ ). Consequently, previous studies that only analyzed the pipe instead of the whole constructive solution were omitting a significant part of the impacts. No significant differences were found between constructive solutions with different plastic pipe materials. In contrast, GFRP and DI had a much larger impact than HDPE and PVC for $200 \mathrm{~mm}$ constructive solutions (around two times higher for GFRP and 5 for DI) due to the higher impacts of these materials.

\subsection{Sewer Network}

Table 22.4 shows the environmental impact of concrete, PVC, and HDPE sewer pipes with different trench designs. Sewer pipes with a diameter of $300 \mathrm{~mm}$ were considered because they are widely used in medium-sized cities. The environmental burdens of sewer pipes were related to a functional unit of 1 linear meter of network 
for a timeframe of 50 year, considering the different lifespan of the materials (i.e., 100 years for concrete and 50 for PVC and HDPE). The sewer operation was excluded from the assessment, given that the electricity required for pumping wastewater depends on the configuration of the city.

In terms of GWP, concrete pipes scored better than plastic pipes, mainly because of their longer durability. The composition of plastic pipes (i.e., oil-based materials) derived in a larger amount of $\mathrm{CO}_{2}$ eq. emissions than in the case of concrete (i.e., mainly cement). There were also differences related to the trench designs that can be applied to each pipe material. In a first attempt to compare constructive solutions, two configurations were assigned to each pipe material: sand beddings (PP1), concrete beddings (PP2 and $\mathrm{CP} 2$ ), and mixed beddings (CP1). PP2 and $\mathrm{CP} 2$ resulted in greater environmental impacts because of the contribution of concrete to the GWP (>80\%). In general, the installation stage accounted for more than $70 \%$ of the total life cycle impacts when PP2 and CP2 were applied. At the end, it was determined that concrete pipes with $\mathrm{CP} 1$ trenches were the most environmentally friendly alternative (Petit-Boix et al. 2014).

\section{Discussion}

\subsection{Optimizing the Urban Fabric Design}

Table 22.5 shows the GWP of two street profiles, which were composed considering the best and worst designs identified in Sect. 3 . The most environmentally-friendly design option for the street profile resulted in a carbon footprint of 1.1 tones of $\mathrm{CO}_{2}$ eq. The best design included concrete sidewalks, asphalt pavements, HDPE gas pipes, PVC, water pipes and concrete sewer pipe with $\mathrm{CP} 1$ trench. In general, the environmental impacts were reduced by $23 \%$ with respect to the worst street profile. The use of granite in sidewalks, LDPE in water supply pipes and HDPE in the sewer system with PP2 trenches were the least recommended design options due to the increase in the GWP.

Table 22.5 Global warming potential (GWP) ( $\mathrm{kg}$ of $\mathrm{CO}_{2}$ eq.) of the best and worst designs of a $1 \times 8 \mathrm{~m}$ street section in a time frame of 50 years

\begin{tabular}{l|l|l|l|l|l|l}
\hline & Sidewalk & Pavement & Gas & Water & Wastewater & Total \\
\hline Best design & Concrete & Asphalt & HDPE & PVC & Concrete CP1 & - \\
\hline GWP & 316 & 504 & 125.8 & 49.6 & 115.8 & 1111.2 \\
\hline$(\%)$ & 28.4 & 45.3 & 11.3 & 4.6 & 10.4 & 100 \\
\hline Worst design & Granite & Asphalt & HDPE & LDPE & HDPE PP2 & - \\
\hline GWP & 436 & 504 & 125.8 & 56.8 & 342 & 1464.6 \\
\hline$(\%)$ & 29.8 & 34.4 & 8.6 & 3.9 & 23.3 & 100 \\
\hline
\end{tabular}


When focusing on the different sub-systems, the asphalt pavement had the greatest contribution to the total GWP because the light-weight traffic road had the largest surface in the street profile $\left(6 \mathrm{~m}^{2}\right)$. Nevertheless, there are two elements that presented the greatest room for improvement. In both scenarios, the concrete sidewalk accounted for almost $30 \%$ of the impacts. Generally, this material is widely applied to pedestrian sidewalks, although asphalt is also used given its low initial cost. Thus, the elements of the paved skins contributed the most to the urban fabric environmental profile, due to a more intensive maintenance of these exposed areas. However, this might depend on the traffic density, the type of mobility and the land use (e.g., pedestrian areas).

The second element that presented variations in the best and worst designs was the sewer network. In this case, the lifespan (i.e., required reposition) also played an important role: when concrete pipes (lifespan: 100 years) were included in the best scenario, they accounted for $10 \%$ of the impacts; in contrast, the contribution of the sewer increased up to $23.3 \%$ when plastic pipes were considered (lifespan: 50 years). Hence, the integration of life-cycle environmental data and service-life planning information is essential for urban planners for identifying long-term environmentally friendly constructive solutions (Mendoza et al. 2012b). Finally, it was detected that the installation of subterranean pipelines had a great contribution to the total GWP and this trend could be extrapolated to other subterranean systems such as telecommunication and electricity networks.

Another key issue is the variation in the street configuration. This study presented a standard street profile, which consisted of common pipe diameters and trench designs. Nonetheless, the population density and the configuration of the city might demand larger pipe diameters because of a more intensive gas and water consumption and wastewater production. Therefore, the contribution of these elements to the total impact of the urban skin might increase. As a result, urban planners must focus on the possible material and installation alternatives that best suit their case studies (Petit-Boix et al. 2014).

\subsection{Towards Smart Grids and Self-sufficiency}

Because networks present a relevant environmental contribution to the impacts of the street, the cities of the future should consider approaching smart grids and selfsufficiency. In this sense, decentralization of urban services is essential to improve the environmental performance of cities. This approach aims to reduce the required networks to supply services while increasing the independence of individual neighborhoods and buildings. From an environmental point of view, this would contribute to reducing the environmental burdens of the subterranean profile of cities. This strategy is particularly meaningful in low-density settlements where longer networks are installed. In the case of gas distribution, when an isolated house requires more than $69 \mathrm{~m}$ of neighborhood network, the installation of individual propane tanks becomes favorable in terms of GWP (Oliver-Solà et al. 2009a). Furthermore, the gas 
supply through district heating systems can be considered as an alternative at the neighborhood scale (Oliver-Solà et al. 2009b).

In the framework of decentralization, self-supply of endogenous resources such as water or energy contributes to the environmental improvement of urban areas. In this case, besides being independent of the central network, local and renewable resources substitute the consumption of nonrenewable ones. For instance, rainwater harvesting systems are increasingly implemented for nonpotable purposes and play a key role in countries dealing with water scarcity. In addition, wastewater recycling can also be integrated in the water metabolism of buildings.

\section{Conclusions}

LCA literature has dealt with the environmental impacts of multiple elements of the urban fabric. However, studies only showed the individual performance of certain elements. This study compiled LCA data in an attempt to quantify the environmental burdens of an entire street profile as a whole, thereby combining the impacts of the elements that constitute the urban fabric: the paved skins and the subterranean networks. The best and worst practices were identified.

The best practices in the design of streets accounted for a carbon footprint of $1.1 \mathrm{t}$ of $\mathrm{CO}_{2}$ eq. This design consisted of concrete sidewalks, asphalt pavements, HDPE gas pipes, PVC water pipes, and concrete sewer pipe with CP1 trench. When considering this configuration in urban planning, the global warming potential of streets can be reduced by $23 \%$. The most impacting scenario included the following practices: granite in sidewalks, LDPE in water supply pipes and HDPE in the sewer system with PP2 trenches. Pavements and sidewalks are the most contributing elements to the overall environmental burdens of streets, mainly because their exposition intensifies their maintenance.

Proper urban fabric design must consider three key aspects: the material selection, lifespan and, in the case of subterranean networks, the installation procedures. First, promoting cleaner production in the construction materials sector (e.g., granite production, Mendoza et al. 2014b) is essential to reduce the environmental burdens of constructive assets and achieve major environmental improvements at city level. Second, lifespan must be included in the design parameters of long-term urban planning. Third, the installation of subterranean networks has a relevant contribution to the total impacts and must be adapted to the technical and environmental requirements of the construction site.

Studies that quantify the environmental burdens of urban elements provide basic information for the decision-making process when environment is considered in urban planning. Thus, the application of life cycle thinking implies the inclusion of environmental criteria during the conception of cities. Towards a sustainable design of cities, urban planning studies might also integrate the social and economic dimensions in the decision-making process. From a life cycle perspective, Social Life Cycle Assessment (S-LCA) (UNEP/SETAC 2009) and Life Cycle Costing (LCC) (ISO 2008) methods may provide a standard quantitative way to assess urban elements. 
Open Access This chapter is distributed under the terms of the Creative Commons Attribution Noncommercial License, which permits any noncommercial use, distribution, and reproduction in any medium, provided the original author(s) and source are credited.

\section{References}

Ash C, Jasny BR, Roberts L, Stone R, Sugden A (2008) Reimagining cities - introduction. Science 319(5864):739-739

European Union (2011) Cities of tomorrow: challenges, visions, ways forward. Report KN-31-11289-EN-C. Unit C.2 - Urban Development, Territorial Cohesion, Directorate General for Regional Policy, Publications Office of the European Union, Luxembourg

IPCC (2007) Contribution of working groups I, II and III to the fourth assessmevnt report of the intergovernmental panel on climate change. Intergovernmental Panel on Climate Change, Geneva

ISO (2006) ISO 14040: environmental management - life cycle assessment - principles and framework. International Organization for Standardization, Geneva

ISO (2008) Buildings and constructed assets - service-life planning - part 5: life-cycle costing. ISO, Geneve

Kamal-Chaoui L, Robert A (2009) Competitive cities and climate change. OECD Regional development working papers 2009/2. Organisation for Economic Cooperation and Development (OECD), Directorate for Public Governance and Territorial Development

Lazaroiu GC, Roscia M (2012) Definition methodology for the smart cities model. Energy 47:326-332

Mendoza J-MF, Oliver-Solà J, Gabarrell X, Josa A, Rieradevall J (2012a) Life cycle assessment of granite application in sidewalks. Int J Life Cycle Assess 17:580-592

Mendoza J-MF, Oliver-Solà J, Gabarrell X, Rieradevall J, Josa A (2012b) Planning strategies for promoting environmentally suitable pedestrian pavements in cities. Transp Res Part D Transp Environ 17:442-450

Mendoza J-MF, Feced M, Feijoo G, Josa A, Gabarrell X, Rieradevall J (2014a) Life cycle inventory analysis of granite production from cradle to gate. Int J Life Cycle Assess 19(1):153-165

Mendoza J-MF, Capitano C, Peri G, Josa A, Rieradevall J, Gabarrell X (2014b) Environmental management of granite slab production from an industrial ecology standpoint. J Clean Prod 84:619-628

Oliver-Solà J, Gabarrell X, Rieradevall J (2009a) Environmental impacts of natural gas distribution networks within urban neighborhoods. Appl Energ 86:1915-1924

Oliver-Solà J, Gabarrell X, Rieradevall J (2009b) Environmental impacts of the infrastructure for district heating in urban neighbourhoods. Energ Policy 37:4711-4719

Oliver-Solà J, Josa A, Rieradevall J, Gabarrell X (2009c) Environmental optimization of concrete sidewalks in urban areas. Int J Life Cycle Assess 14:302-312

Pacione M (2009) Urban geography. a global perspective. Routledge, Oxon

Petit-Boix A, Sanjuan-Delmás D, Gasol CM, Villalba G, Suárez-Ojeda ME, Gabarrell X, Josa A, Rieradevall J (2014) Environmental assessment of sewer construction in small to medium sized cities using life cycle assessment. Water Resour Manag 28:979-997

Sanjuan-Delmás D, Petit-Boix A, Gasol CM, Villalba G, Suárez-Ojeda ME, Gabarrell X, Josa A, Rieradevall J (2014) Environmental assessment of different pipelines for drinking water transport and distribution network in small to medium cities: a case from Betanzos. Spain J Clean Prod 66:588-598

UN (2013) Towards sustainable cities. World Economic and Social Survey 2013. Sustainable Development Challenges. United Nations (UN), Department of Economic and Social Affairs, New York 
UNEP/SETAC (2009) Guidelines for a social life cycle assessment. UNEP, Paris

UNEP/SETAC (2012) Greening the economy through life cycle thinking - ten years of the UNEP/ SETAC Life Cycle Initiative. United Nations Environment Programme (UNEP) and Society of Environmental Toxicology and Chemistry (SETAC), Nairobi

UN-HABITAT (2013a) The relevance of street patterns and public space in urban areas. UN-Habitat working paper, United Nations Human Settlements Programme (UN-Habitat), Nairobi

UN-HABITAT (2013b) Streets as public spaces and drivers of urban prosperity. United Nations Human Settlements Programme (UN-Habitat), Nairobi

UN-HABITAT (2013c) Urban planning for city leaders. United Nations Human Settlements Programme (UN-Habitat), Nairobi

UN-HABITAT (2013d) Revised compilation for sustainable cities and human settlements in the sustainable development goals (SDGs) within the Post-2015 development agenda. United Nations Human Settlements Programme (UN-Habitat), Nairobi

UN-HABITAT (2014) Public Space in the global agenda for sustainable urban development: the "global public space toolkit". Urban Planning and Design Branch, United Nations Human Settlements Programme (UN-Habitat), Nairobi

UN Population Division (2010) World urbanisation prospects: the 2009 revision. United Nations (UN), Population division, Department of Economic and Social Affairs, New York

WWF (2008) Reinventing the city: three prerequisites for greening urban infrastructures. World Wildlife Fund (WWF) International, produced in cooperation with Booz and Company, Gland 